\title{
O trânsito urbano e os fatores estressantes percebidos por motoristas de ônibus: estudo fenomenológico
}

\author{
Urban traffic and the stress factors perceived by bus drivers: a phenomenological study \\ El tráfico urbano y los factores estresantes percibidos por los conductores de autobuses: un estudio \\ fenomenológico
}

\author{
Vanessa Carine Gil de Alcantaral; Rose Mary Rosa Costa Andrade Silval'; Eliane Ramos Pereira"l'; \\ Dejanilton Mela da Silva'v; Isadora Pinto Flores ${ }^{V}$
}

\begin{abstract}
RESUMO
Objetivo: discutir as vivências dos motoristas de ônibus através de suas percepções acerca do trânsito e os impactos à saúde sofridos por eles. Método: estudo qualitativo fenomenológico realizado em uma garagem de ônibus situada no Rio de Janeiro. As entrevistas fenomenológicas foram realizadas com 24 motoristas que responderam perguntas semiestruturadas e foram gravadas em dispositivo $\mathrm{mp} 3$, posteriormente, transcritas para obtenção das unidades de significado, a coleta de dados ocorreu entre 2017 e 2018. O projeto foi aprovado por Comitê de Ética e Pesquisa. Resultados: da análise fenomenológica das unidades de significados dos depoimentos emergiram duas categorias: o trânsito é instável e estressante e a falta de educação das pessoas afeta os aspectos psíquicos. $\mathrm{O}$ ambiente de trabalho determina, expressivamente, o bem-estar dos trabalhadores que nele atuam. Conclusão: diante de tantos limites impostos pela sociedade contemporânea e pelo sofrimento no trabalho, necessário é motiva-los, e também dar-lhes condições de realizar seu trabalho de forma plena.
\end{abstract}

Descritores: Enfermagem; Saúde do Trabalhador; Condução de Veículo; Estresse Psicológico.

\begin{abstract}
Objective: to discuss the experience of bus drivers through their perceptions regarding traffic and the health impacts they suffer. Method: in this qualitative phenomenological study conducted at a bus garage in Rio de Janeiro, data were collected in 2017 and 2018 by way of phenomenological interviews of 24 drivers, who answered semi-structured questions. The resulting mp 3 recordings were later transcribed to obtain the units of meaning. The project was approved by the research ethics committee. Results: from phenomenological analysis of the units of meaning in the responses, two categories emerged: traffic is unstable and stressful, and people's lack of education has adverse psychological effects. The work environment substantially determines the well-being of those working in it. Conclusion: given all the many constraints imposed by contemporary society and by their suffering at work, it is necessary to motivate them and also assure them the conditions necessary to carry out their work fully.

Descriptors: Nursing; Occupational Health; Automobile Driving; Stress, Psychological.

\section{RESUMEN}

Objetivo: discutir la experiencia de los conductores de autobuses a través de sus percepciones sobre el tráfico y los impactos en la salud que sufren. Método: en este estudio fenomenológico cualitativo realizado en un garaje de autobuses en Río de Janeiro, se recopilaron datos en 2017 y 2018 a través de entrevistas fenomenológicas a 24 conductores, que respondieron preguntas semiestructuradas. Las grabaciones $\mathrm{mp} 3$ resultantes se transcribieron posteriormente para obtener las unidades de significado. El proyecto fue aprobado por el comité de ética de investigación. Resultados: del análisis fenomenológico de las unidades de significado en las respuestas, surgieron dos categorías: el tráfico es inestable y estresante, y la falta de educación de las personas tiene efectos psicológicos adversos. El ambiente de trabajo determina sustancialmente el bienestar de quienes trabajan en él. Conclusión: dadas las muchas restricciones impuestas por la sociedad contemporánea y por su sufrimiento en el trabajo, es necesario motivarlos y también asegurarles las condiciones necesarias para llevar a cabo su trabajo plenamente. Descriptores: Enfermería; Salud Laboral; Conducción de Veículo; Estrés Psicológico.
\end{abstract}

\section{INTRODUÇÃO}

O trabalho no transporte urbano pode alterar o estado de saúde do sujeito, pois, as exigências do trabalho são uma ameaça ao próprio trabalhador ${ }^{1}$. As condições impostas diariamente ao corpo do motorista como temperaturas elevadas, desajustes dos bancos com a altura do condutor, extensos engarrafamentos, horas sem beber água, desfavorecem a promoção de saúde para esses trabalhadores ${ }^{2}$. Além disso, as condições de ambiente de vida, convívio com os meios sociais e de trabalho influenciam o estado de saúde, de maneira que podem desencadear o surgimento de doenças e/ou alterações psicológicas.

IPsicóloga, Doutora. Universidade Federal Fluminense. Niterói, Brasil. E-mail: vanessagilpsicologa@hotmail.com. ORCID: https://orcid.org/0000-0002-8508-0163. "Enfermeira, Psicóloga e Filósofa. Doutora. Universidade Federal Fluminense. Niterói, Brasil. E-mail: roserosauff@gmail.com. ORCID: https://orcid.org/0000-0002-6403-2349. I"Enfermeira, Psicóloga. Doutora. Universidade Federal Fluminense. Niterói, Brasil. E-mail: elianeramos.uff@gmail.com. ORCID: https://orcid.org/0000-0002-6381-3979. IVEnfermeiro, Doutor. Universidade Federal Fluminense. Niterói, Brasil. E-mail: demedasi@gmail.com. ORCID: https://orcid.org/0000-0002-0800-3658.

VPsicóloga, Mestre. Universidade Federal Fluminense. Niterói, Brasil. E-mail: isadoraflores@outlook.com. ORCID: https://orcid.org/0000-0002-5429-672X.

v'Bolsa de Doutorado financiada pela Fundação Carlos Chagas Filho de Amparo à Pesquisa do Estado do Rio de Janeiro (FAPERJ). 
São muitos os determinantes de saúde que constituem a condição de vida de uma pessoa como trabalhador $(a)^{3}$. São importantes fatores: relações sociais no ambiente de trabalho, alimentação, moradia, saneamento, educação, transporte e lazer. Estes podem influenciar direta ou indiretamente a saúde .

A maneira de dirigir e a estrutura dos ônibus coletivos é a mesma mundo afora, e a profissão do motorista de ônibus dá-se no enlace das habilidades pessoais ${ }^{4}$, atenção e o social; o trabalho é individual, mas a responsabilidade é coletiva. Conhecer para compreender a percepção vivenciada pelos motoristas de ônibus favorece não somente a eles próprios, mas possibilita o reconhecimento de suas necessidades e sintomas; a visibilidade dos impactos do trânsito nesses profissionais permite-nos oferecer escuta e espaço para a compreensão do que experenciam em seu cotidiano e a partir do discurso conhecer suas necessidades e dores.

O estresse é um agravante para a insatisfação do motorista com sua profissão. O desrespeito à ergonomia altera as dimensões cognitivas e fisiológicas do trabalhador, a Organização Mundial de Saúde (OMS) reconheceu-o como um fator de risco por exemplo, para a hipertensão arterial ${ }^{5}$.

As empresas de ônibus possuem em seu efetivo psicólogos que são responsáveis pela gestão de pessoas bem como atuam em treinamentos motivacionais e comportamentais, e no setor médico das empresas, enfermeiros e técnicos de enfermagem realizam atendimento relativos a saúde ocupacional nos processo admissionais e demissionais.

$\mathrm{O}$ atendimento psicológico não é ofertado na lógica organizacional nem atendimentos de enfermagem são realizados. Sabe-se que o cotidiano no tranporte coletivo é dinâmico ${ }^{6}$ e exige muito do corpo e do psiquismo dos motoristas nesta pesquisa prioriza-se o motorista, que é o trabalhador da "imagem" da empresa e o que movimenta a população e a produtividade da organização a não consideração de sua subjetividade, consequentemente, pode induzir ao adoecimento deste trabalhador.

A relevância da pesquisa édar voz ao motorista que experencia diariamente a condição de mover a cidade e que se torna invisivel socialmente e muitas vezesdesrespeitado, justifica-se portanto a necessidade de compreender o que o profissional do transporte coletivo fala e suas percepções, portanto, o presente estudo objetivou discutir as vivências dos motoristas de ônibus através de suas percepções acerca do trânsito e os impactos à saúde sofridos por eles.

\section{REVISÃO DE LITERATURA}

A existência humana é marcada pela sua consciência. A expressão "estar no mundo" (ou personificação) é um conceito que reconhece as ligações físicas das pessoas com seu mundo ${ }^{7}$ - no cotidiano da mobilidade urbana a consciência dos motoristas trabalha e impacta sua corporeidade.

A pesquisa fenomenológica é uma tradução de fenômenos a partir daqueles que a experienciam, em seu cotidiano. Na epoché, o indivíduo se afasta das hipóteses do estudo justamente para não direcionar os possíveis resultados ou para sugerir o caminho; afinal, é a própria descrição e a repetição dos fenômenos que possibilita aos pesquisadores enxergarem a direção que o fenômeno está mostrando ${ }^{8}$.

A condução é uma extensão dos processos internos dos motoristas. A dificuldade de elaboração das emoções no dia a dia não deve ser desprezada, a percepção existe sempre no modo do "Se".

Ela não é um ato pessoal pelo qual eu mesmo daria um sentido novo à minha vida. Aquele que, na exploração sensorial, atribui um passado ao presente e o orienta para um futuro não sou eu enquanto sujeito autônomo, sou eu enquanto tenho um corpo e enquanto sei "olhar?.

As saúdes física e psicológica sofrem impactos ${ }^{9}$, desde as limitações impostas ao corpo até as emoções não ditas, o exterior, ao mesmo tempo, confirma-o na sua particularidade, torna-o visível como ser parcial para o olhar dos outros e, ao mesmo tempo, vincula-o ao todo do Ser ${ }^{6}$.

A vivência dos motoristas de ônibus é desconsiderada pela lógica organizacional, ele não tem um ambiente para escuta psicológica, ou ajuda terapêutica, o corpo do trabalhador, a corporatividade sustenta o transporte urbano ${ }^{9}$, e ao mesmo tempo é invisível e não valorizado.

\section{MÉTODO}

Este estudo é qualitativo fenomenológico. Como critérios de inclusão destaca-se profissionais acima de 26 anos, pois a Carteira Nacional de Habilitação $(\mathrm{CNH})$ para veículos pesados só pode ser retirada a partir de 21 anos de idade, entende-se que o profissional de transporte coletivo deve realizar cursos específicos antes de efetivamente ser contratado para o transporte de pessoas, alguns destes cursos exigem tempo mínimo de $\mathrm{CNH}$, o que explica o critério etário da pesquisa e ainda motoristas com mais de dois anos de profissão. Como critérios de exclusão destaca-se motoristas que exercem outra atividade remunerada e motoristas que se afastaram por mais de 2 anos pelo Instituto Nacional de Seguridade Social. 
A proposta do estudo foi apresentada aos participantes, assim como a leitura e explicação do Termo Livre e Esclarecido, a fim de orientar sobre possíveis questionamentos, de acordo com as especificações éticas e legais da Resolução CNS 466/12 ${ }^{10}$, do Ministério da Saúde.

A coleta de dados aconteceu pela entrevista fenomenológica com uma questão norteadora: Como você vivencia o trânsito? Gravada em aparelho de mp3, as entrevistas aconteceram entre julho de 2017 a janeiro de 2018, numa sala privativa cedida pelos Recursos Humanos da empresa-campo, em uma garagem de ônibus de grande porte na zona leste do Rio de Janeiro, a proposta da pesquisa foi apresentada para os motoristas por técnica de snow ball, foram convidados 90 motoristas e 24 profissionais responderam às perguntas da entrevista fenomenológicas, individualmente. A média de idade foi de 41,6 anos e 11 anos de profissão. A análise dos dados foi realizada por transcrições das entrevistas ${ }^{11}$ e categorização seguindo os pressupostos da metodologia descritiva fenomenológica: o primeiro passo envolveu a leitura criteriosa das transcrições das entrevista gravadas dos participantes da pesquisa, com o propósito de alcançar o sentido da percepção do vivido, apreendendo o fenômeno em questão, conservando a linguagem de expressão do sujeito; o segundo passo correspondeu à identificação de significados descritos pelos participantes da pesquisa que são percebidos pelo pesquisador de forma espontânea em meios às transcrições; o terceiro passo requereu a transformação da linguagem do participante em linguagem cientifica, mantendo a ênfase do fenômeno ${ }^{12}$ descrito.

O último passo foi sintetizar e associar as unidades de significados, chegando ao núcleo do significado do fenômeno. O projeto de estudo foi aprovado Comitê de ética e pesquisa (CEP) da Faculdade de Medicina da Universidade Federal Fluminense (UFF), CAAE no 64110016.2.0000.5243. Para assegurar o anonimato dos participantes, utilizou-se a letra E (entrevistado) e o número de ordem de participação no estudo. Exemplo: E1, E2.

\section{RESULTADO E DISCUSSÃo}

Da análise das entrevistas emergiram as categorias $O$ trânsito é instável e estressante e $A$ falta de educação das pessoas afeta os aspectos psíquicos, que serão abordadas a seguir.

\section{0 trânsito é instável e estressante}

A realidade brasileira quanto ao transporte urbano desponta as condições de má preservação e manutenção dos ônibus ${ }^{13}$

Os efeitos psicológicos do trabalho ${ }^{14}$ para os motoristas de ônibus são inerentes às demandas físicas, muitas vezes as emoções negativas, as limitações vivenciadas no cotidiano escoam para o corpo do motorista.

A instabilidade do trânsito e os efeitos nos entrevistados:

Uma coisa que não pode prever, uma hora você está tranquila em outra as pessoas fazem coisas que não devem, jogam o carro em cima de você, as vezes tenho dificuldades no trânsito porque tem outras pessoas irresponsáveis. (E1)

É estressante por causa do passageiro enjoado, isso estressa o motorista. (E3)

Às vezes fico estressado. Eu sou daquele que se ficar quieto [...], aquela coisa fica remoendo. [...] então, é por isso que e pego e falo. [...] sai! E pra sair o estresse mesmo, legal, eu tenho que sair de dentro do carro e chegar ao ponto final. (E6)

É, tipo assim, não vai me deixar passar, não? Tudo bem! Quando você me pedir uma passagem, também não vou te dar. Eu vou ser ruim também com você". (E7)

O trânsito é uma arma, é complicado, o trânsito fere, mata, amputa. (E9)

O trânsito, atualmente, poderia ser melhor, mais pacífico, menos violento, mas, ultimamente, a gente sabe, né, essas coisas que estamos vivenciando aí, essas tragédias. (E13)

A minha tensão chega a ser apreensiva. Eu estou ligado a toda hora porque a toda hora pode acontecer qualquer coisa, (estala os dedos) assim, e você, com um veículo grande, as proporções são maiores (E15)

Quando eu entrei eu sabia o que eu iria enfrentar o próprio nome já diz trânsito, enfrentar trânsito bom, trânsito caótico, aquelas pessoas que querem entrar na sua frente, pedestre, ciclista, motociclista. (E16)

Minha vivência no trânsito é muito estressante, principalmente nos horários de pico, todo mundo querendo chegar no seu trabalho, todo mundo atrasado, a falta de educação, um querendo passar na frente do outro, ninguém dá a vez para ninguém. (E22)

O trânsito é espaço, é sistema, é interação social, é o deslocamento composto por variados transportes, sendo o ônibus um instrumento, o motorista um trabalhador, e a população usuária. O trânsito é a reunião desses aspectos em ação, em movimento, em interação. 
Por inúmeras causas, o trânsito deixou de ser apenas espaço de deslocamento e passou a ter conotação de caos, de perigo iminente, recordes de engarrafamentos, como condição estressante inerente à vida urbana.

O contexto urbano especificamente da cidade do Rio de Janeiro com a violência urbana acentuada os motoristas de ônibus enfrentam o estresse causado também pela eminência de um episódio de insegurança gerada por roubos, tiros de arma de fogo, mortes de passageiros em assaltos por exemplo, a insegurança nos engarrafamentos é grande pois a população em protestos utilizam ônibus como barreira para a passagem de veículos e ateiam fogo no coletivo motivados pela violência urbana.

Não bastassem todas as limitações fisicas ${ }^{15} \mathrm{e}$ sociais sentidas pelos motoristas de ônibus, os transtornos psicológicos ocupacionais estão presentes no cotidiano desses trabalhadores.

As exigências internas das empresas causam estresse nos profissionais ${ }^{16}$. 0 tempo de profissão está relacionado ao aparecimento de estresse, a perda de humor, ao mal-estar generalizado sem razão específica e ao cansaço constante, bem como o excesso de carga de trabalho ocasiona horas fatigantes e compromete as articulações dos motoristas de ônibus, por exemplo.

A atuação interdisciplinar nas garagens de ônibus com o suporte de saúde ocupacional contemplando a educação em saúde, com palestras, informativos prevenção e saúde ocupacional e a Psicologia, em consonância com tais práticas preventivas, pode intervir na significação das demandas psíquicas, oferecendo uma escuta qualificada e sensibilizada.

Os treinamentos motivacionais, de capacitação, devem fazer parte da rotina das empresas de transporte coletivo. Promover a capacitação dos trabalhadores prepara e contribui para a saúde mental.

O motorista de ônibus é condutor da máquina que dirige, na visão organizacional, mas há necessidade de considerar os processos físicos e psicológicos em questão no trabalho diário. O mundo do(a) profissional insere uma terceira responsabilidade: o cuidado ao(à) motorista.

As representações do estado psíquico dos motoristas vêm de forma sensível, olhando para frente, percebe-se cansado ${ }^{17}$ e nervoso, e seus movimentos dentro do ônibus são pontos de impactos e partes de si no momento do trabalho, o que não dá para expressar em linguagem, retornando ao mundo com gestos, com alterações nas emoções.

\section{A falta de educação das pessoas afeta os aspectos psíquicos}

Difícil tarefa de equilibrar o serviço de transporte e a satisfação do usuário, ainda mais complexa a relação entre o cotidiano rotineiro e a satisfação no contexto de trabalho para os motoristas profissionais é um movimento de equilíbrio exige esforços de todas as partes envolvidas.

No contexto do trabalho, é imprescindível salientar que as reclamações dos profissionais não permearam as condições de trabalho e nem o salário. Os aspectos de identificação da profissão e do dia a dia em suas atividades são modos de operacionalizar as possíveis melhorias no que tange a visão do outro sobre o trabalho.

O espaço do trânsito e o comportamento dos condutores:

o brasileiro no trânsito está sem educação, entendeu? Ele acha que ele tem um determinado carro, ele é o dono da rua, ele se acha o melhor, ele avança o sinal. Você está atravessando, ele passa, não está nem aí, entendeu? (E4)

Ninguém respeita ninguém. Ninguém tem educação, e educação no trânsito, se não tem, se tem mesmo, $e$ ninguém respeita, né, avanço de sinal. (E10)

Hoje em dia, eu estou vendo o trânsito, ele muito caótico em relação à educação, em relação à formação de motoristas. (E18)

Os motoristas de carro moto eles não querem saber, eles querem ser os primeiros não se preocupam se vão bater, se vão atropelar eles [...] é fácil culpar a gente por qualquer avaria que venha acontecer (E19)

Quando eu vejo que vem aquele passageiro mal-humorado, eu finjo que não estou olhando. Eu olho pra outra coisa. [...] Olho pra outra coisa. Mais ou menos assim. Pra não ter problema. Pra não ter problema. Porque, tipo assim, a minha Psicologia é evitar o problema. (E21)

No trânsito o que eu tenho percebido nesses anos é que as pessoas estão mais individualistas cada um quer seu espaço e direito, ela não pensa que onde acaba o dela começa o do outro, hoje em dia para você dirigir está muito complicado. (E24)

Não bastassem todas as limitações físicas sentidas pelos motoristas de ônibus ao redor do mundo, os transtornos mentais comuns estão presentes no cotidiano desses trabalhadores. A falta de atividades socioculturais, a violência, agressões sofridas tanto por parte dos passageiros como alteram o comportamento dos motoristas e a resposta psíquica cronifica sintomas mentais ${ }^{18}$. Trabalhar no transporte coletivo torna-se um ato de resistência física e mental na realidade do país ${ }^{19}$. 
As exigências as quais os motoristas de ônibus estão submetidos vão além da empresa, do corpo, da mente; perpassam a educação individual. Nos relatos acima descritos, é possível compreender que as afetações dessa vivência são sentidas pela falta de educação dos demais condutores.

Na relação com o passageiro ${ }^{20}$, parte inafastável do trabalho de dirigir o motorista de ônibus experiência um misto de sentimentos, desde a satisfação de executar o trabalho de conduzir pessoas ao destino desejado a problemas gerados por incompatibilidade de opiniões ou acusações de ambas as partes.

Estamos fundamentados na experiência, mas essa perpassa a nossa subjetividade ${ }^{22}$. O que foi possível compreender desta categoria é que a relação com o trânsito não está diretamente ligada ao tempo de profissão.

O modo de lidar com a vivência independe da quantidade de anos que os profissionais possuem exercendo a função. Diante das condições surpreendentes das horas de trabalho, há necessidade de se reinventar e lidar com os mais variados comportamentos e conflitos.

Entende-se como limitação do presente estudo a escassez de estudos que a própria complexidade do método fenomenológico necessitando de uma aguçada percepção para transformar o dado de pesquisa em linguagem fenomenológica.

\section{CONCLUSÃO}

Estudos sobre seu estilo de vida e os fatores psicossociais aos quais estão submetidos se fazem necessários para uma compreensão ampliada dos modos como este profissional reage às intempéries da profissão.

$\mathrm{Na}$ análise dos estudos compreendemos que dirigir possui vários estressores: o relacionamento intrincado com os clientes, o próprio trânsito, o calor muitas vezes intenso na cabine, as condições do veículo, as condições de saúde ao longo da jornada do trabalho e a carga horária intensa.

As empresas não têm controle sobre o trânsito, e os motoristas de ônibus têm inúmeras cobrança em seu trabalho, as relações na organização são inafastáveis. As cobranças por quantidade de passageiros e metas a serem batidas de combustível e economia dele, configuram uma pressão organizacional para que ele não atrase a viagem, garantindo a pontualidade dos serviços prestados aos passageiros.

O cuidado está além do corpo, a Psicologia possui responsabilidades que transcende os Recursos Humanos, em consonância com a Enfermagem, o desenvolvimento de palestras, folhetos informativos, são ferramentas de disseminação do conhecimento e promotoras de cuidado. O enfermeiro poderá ser reconhecido pela capacidade de compreender a necessidade de atendimento e construir o encontro humanizado, com qualificação na escuta e parceria colaborativa com o motorista de ônibus.

Necessária é a preservação do corpo como parte do processo de trabalho e alterar a lógica organizacional que prioriza a produção e descuida do trabalhador, tendo na produtividade a essência do trabalho perde-se o fator principal: o humano.

\section{REFERÊNCIAS}

1. Marrara T. Public transport and urban development: legal aspects of the National Mobility Act. Revista Digital de Direito Administrativo. 2015 [cited 2019 Jan 13]; 2(1): 120-36. DOI: https://doi.org/10.11606/issn.2319-0558.v2i1p120-136

2. Orozco-Solis MG, Colunga-Rodríguez C, Preciado-Serrano ML, Ángel-González M, Vázquez-Colunga JC, Colunga-Rodríguez BA. Representation of self-care of health at work among urban bus drivers in Guadalajara, Mexico. Cad. Saúde Pública. 2017 [cited 2019 Jan 13]; 33(3): e00139815. DOI: http://doi.org/10.1590/0102-311x00139815

3. Ministério da Saúde (Br). Resolução 466/2012. Diretrizes e normas regulamentadoras de pesquisas envolvendo seres humanos. Brasília (DF): 2012. [cited 2019 May 2]; Available from: https://bvsms.saude.gov.br/bvs/saudelegis/cns/2013/res0466_12_12_2012.html

4. Matias C, Sales MM. Malabarismo no trânsito: o trabalho do motorista do transporte coletivo em dupla função. Revista PRETEXTOS. Dossiê - Contribuições da Psicologia para os serviços de Saúde. 2017 [cited 2020 May 05]; 2(4): 157-74. Available from: http://periodicos.pucminas.br/index.php/pretextos/article/view/15250

5. Jayarajah U, Jayakody AJA, Jayaneth MBJN, Wijeratne S. Prevalence of hypertension and its associated factors among a group of bus drivers in Colombo, Sri Lanka. Int J Occup Environ Med. 2017 [cited 2019 Feb 6]; 8:58-59. Available from: https://www.theijoem.com/ijoem/index.php/ijoem/article/view/986/820

6. Zamboni J, Barros MEB. Paradox of the bus drivers who struggle: between social movements for urban mass transit, the work in the bus. Rev. psicol. polít. 2014 [cited 2019 Feb 6]; 14(29): 53-69. Available from: http://pepsic.bvsalud.org/scielo.php?script=sci_arttext\&pid=S1519-549X2014000100005\&lng=pt\&tlng=pt

7. Merleau-Ponty, M. Fenomenologia da percepção. 4a ed. São Paulo: Martins Fontes. 2011.

8. Kafle NP. Hermeneutic phenomenological research method simplified. Bodhi: AnInterdisciplinary Journal. 2011 [cited 2019 Feb 7]; 5(1):181-200. DOI: https://doi.org/10.3126/bodhi.v5i1.8053 
9. Alcantara VCG de; Silva RMRCA; Pereira ER. The working conditions and the lifeworld of bus drivers: phenomenological study. Rev. enferm. UERJ. 2016 [cited 2019 May 9]; 24(6):e12514. DOI: https://doi.org/10.12957/reuerj.2016.12514

10. Ministério da Saúde (Br). Resolução 466/2012. Diretrizes e normas regulamentadoras de pesquisas envolvendo seres humanos. Brasília (DF): 2012. [cited 2019 May 2]; Available from: https://bvsms.saude.gov.br/bvs/saudelegis/cns/2013/res0466_12_12_2012.html

11. Silva AL, Silva LF, Souza IEO, Guedes MVC, Araújo MAM, Farias MS. Being a woman with a heart disease and developing pressure ulcer as a hospital inpatient: sense of fear. Rev. enferm. UERJ. 2017 [cited 2019 May 3]; 25:e14509. DOI: https://doi.org/10.12957/reuerj.2017.14509

12. Alcantara VCG, Silva RMCRA, Pereira ER, Silva DM, Flores IP. The experience in traffic and its effects on the health of bus drivers: a phenomenological descriptive study. Revista de Enfermagem Referência. 2019 [cited 2020 May 3]; IV Série. 21-30. DOI: https://doi.org/10.12707/RIV19049

13. Alonso F, Esteban C, Sanmartín J, Useche SA. Reported prevalence of health conditions that affect drivers. Cogent Medicine. 2017 [cited 2019 Feb 5]; 4:1303920. Available from: https://www.tandfonline.com/doi/full/10.1080/2331205X.2017.1303920

14. Useche SA, Montoro L, Alonso F, Pastor JC. Psychosocial work factors, job stress and strain at the wheel: validation of the copenhagen psychosocial questionnaire (COPSOQ) in Professional Drivers. Front Psychol. 2019 [cited 2019 May 10]; 10:1531. DOI: http://doi.org/10.3389/fpsyg.2019.01531

15. Prado RL, Vargas MM, Silva MHS. Estresse e atividade física em motoristas de ônibus urbano em uma capital do nordeste do Brasil. 2017 [cited 2019 Jun 16]; 5(3):37-46. Available from: https://periodicos.set.edu.br/index.php/saude/article/view/4431

16. Martins FF, Lopes RMF, Farina M. Public transportation driver's level of stress and main stressors. Bol. - Acad. Paul. Psicol. 2014 [cited 2019 Feb 4]; 34 (87): 523-36. Available from: http://pepsic.bvsalud.org/scielo.php?script=sci_arttext\&pid=S1415$711 \times 2014000200014 \&$ Ing=es\&tlng=pt.

17. Estember RD, Huang CJHJ. Essential Occupational Risk and Health Interventions for Taiwan's Bus Drivers. In: 6th International Conference on Industrial Engineering and Applications. Tokyo: ICIEA, 2019 [cited 2019 Jun 14]; 273-77. DOI: https://doi.org/10.1109/iea.2019.8714964

18. Useche SA, Cendales B, Montoro L, Esteban C. Work stress and health problems of professional drivers: a hazardous formula for their safety outcomes. Peer J. 2018 [cited 2019 Jun 14]; 6:e6249. DOI: https://doi.org/10.7717/peerj.6249

19. Useche S, Alonso F, Cendales B, Autukevičiūtè R, Serge A. Burnout, occupational stress, health and road accidents among bus drivers: barriers and challenges for prevention. J Environ Occup Sci. 2017 [cited 2019 May 2]; 6(1):1-7. DOI: https://doi.org/10.1016/j.shaw.2018.01.003

20. 20.Zhang Z, Zhang X, Ji N, Lin S, Wang K, Ma T, et al. A Study on the differences in driving skills of chinese bus and taxi drivers. J Adv Transp. 2019 [cited 2019 Jun 10]; 1-9. DOI: https://doi.org/10.1155/2019/8675318

21. Carvalho PL, Malhado SCB, Constâncio TOS, Ribeiro ÍJ S, Boery RNSO. Sena ELS. Cuidado humano à luz da fenomenologia de Merleau-Ponty. Texto contexto - enferm. [Internet]. 2019 [cited 2020 May 07]; 28: e20170249. DOI: https://doi.org/10.1590/1980-265x-tce-2017-0249

22. Rueda FJM, Serenini ALP, Meireles E. Relationship between quality of work life and trust employee in the organization. Rev. Psicol. Organ. Trab. 2014 [cited 2019 Jan 14]; 14(3):303-314. Available from: http://pepsic.bvsalud.org/scielo.php?script=sci_arttext\&pid=S1984-66572014000300006\&lng=pt\&nrm=iso 